Vako Ilia. Didactic biomechanics: a modern trend of scientific research. Pedagogy and Psychology of Sport. 2020;6(1):152-161. eISSN 2450-6605. DOI http://dx.doi.org/10.12775/PPS.2020.06.01.012

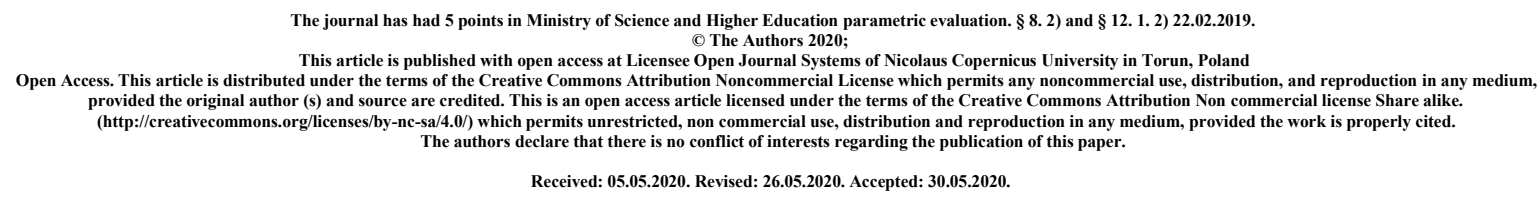

ДИДАКТИЧНА БІОМЕХАНІКА: СУЧАСНИЙ ТРЕНД НАУКОВИХ ДОСЛІДЖЕНЬ

\title{
DIDACTIC BIOMECHANICS: A MODERN TREND OF SCIENTIFIC RESEARCH
}

\author{
Ilia Vako \\ Ілля Вако
}

Blak Sea National University named after Petro Mohyla, Nikolaev, Ukraine Чорноморський національний університет імені Петра Могили, м. Миколаїв

Анотація. Ілля Вако. Дидактична біомеханіка: сучасний тренд наукових досліджень. Чорноморський національний університет імені Петра Могили, м. Миколаїв.

Актуальність. Рухи людини підкоряються всім фізичним законам, які визначають рух будь-якого матеріального тіла на Землі. Це - i закон всесвітнього тяжіння, і закони Ньютона, і закони гідроаеромеханіки, коливальних і хвильових явищ. Переважна більшість рухів людини виконується 3 певною метою i відноситься до числа довільних. Такі руху входять до складу рухових дій, в сукупність елементарних рухових актів, спрямованих на досягнення певної мети. У кожному руховому акті присутні орієнтовна, виконавча і контрольна частини. Рухи людини і їх вдосконалення слід розглядати як результат не просто взаємодії із зовнішнім середовищем, а взаємодії, при якому фізичні властивості зовнішнього середовища цілеспрямовано змінюються. А це означає, що таким способом можна цілеспрямовано впливати на сам характер руху через пристосувальні рухові реакції людини в умовах безперервного взаємодії із зовнішнім середовищем (то, що можна назвати зовнішнім управлінням). Отже, в управлінні рухами існують внутрішня i зовнішні системи управління, узгоджене функціонування яких дозволяє побудувати рухову дію людини. Завдання дослідження - провести порівняльний біомеханічний аналіз техніки виконання прийомів «важіль ліктя назовні», «важіль ліктя всередину» та «кидок із захватом ніг ззаду» працівниками 3 досвідом роботи та курсантами четвертого року навчання з використанням оптико-електронної 
системи «Qualisys». Методи дослідження. Для виконання поставлених завдань використано такі методи дослідження, як аналіз науково-методичної літератури й документальних матеріалів, методи реєстрації та аналізу рухів спортсмена (система відеореєстрації та аналізу рухів спортсмена 3D реєстрації рухів людини «Qualisys Motion Capture»). Результати, отримані в процесі дослідження, було оброблено 3 використанням методів математичної статистики. Результати дослідження. Результати досліджень свідчать про наявність як загальних відмінностей у техніці виконання цих прийомів (загальна тривалість виконання прийому; етапність вирішення рухових завдань (паралельність або послідовність виконання рухових дій); техніка ударних дій), так і часткових, які характерні для окремих складових конкретного прийому (тривалість і послідовність окремих дій у загальній структурі прийому; характер та особливості їх виконання). Головною відмінністю, яка слугує одночасно найбільш вагомим біомеханічним критерієм ефективності реалізації прийомів, $\epsilon$ тривалість часу.

Висновки. Результати порівняльного аналізу техніки виконання прийомів працівниками 3 досвідом роботи та курсантами четвертого року навчання дали змогу встановити, що склад рухових дій у цих групах однаковий, тобто відбуваються захвати, присутні ударні дії, медіальні й латеральні оберти верхніх кінцівок умовного правопорушників та інше. Однією з найбільш важливих особливостей є структурна послідовність цих рухових дій.

Ключові слова: відеореєстрації техніки рухових дій, прийоми «важіль ліктя назовні», «важіль ліктя всередину» та «кидок із захватом ніг ззаду».

\section{Abstract. Ilia Vako. Didactic biomechanics: a modern trend of scientific research. Blak Sea National University named after Petro Mohyla, Nikolaev, Ukraine.}

Topicality. Human movements obey all the physical laws that determine the motion of any material body on the Earth. They include the law of gravity, and Newton's laws, and the laws of hydro-aeromechanics, vibrational and wave phenomena. The vast majority of human movements are performed for a specific purpose and are arbitrary. Such movements are part of motor actions, a set of elementary motor acts aimed at achieving a certain goal. Each motor act consists of indicative, executive and control parts. Human movements and their improvement should be considered as the result of not just interaction with the external environment, but also interaction in which the physical properties of the external environment are purposefully changed. This means that in this way one can purposefully influence the very nature of movement through the adaptive motor reactions of a human in a continuous interaction with the external environment (which can be called external control). Thus, there are internal and external control systems in the management of movements, the coordinated operation of which allows building a motor action of a human. The task of the study is to conduct a comparative biomechanical analysis of the technique of performing the techniques of "elbow lever outward", "elbow lever inward" and "throw with legs grab behind" by experienced workers and cadets of the fourth year of study with the help of optoelectronic system "Qualisys". Research methods. To achieve the set tasks, we have applied such research methods as analysis of scientific and methodological literature as well as documentary materials, methods of registration and analysis of athlete's movements (system of video recording and analysis of athlete's movements, 3D recording of human movements "Qualisys Motion Capture"). The results obtained during the study have been processed with the help of mathematical statistics methods. Results of the research. The results of research indicate the presence of general differences in the technique of performing these drills (total duration of a drill performance; phases for motor tasks 
solution (parallelism or sequence of motor actions); technique of motor actions)) as well as partial differences, which are characteristic of individual components of a particular technique (duration and the sequence of individual actions in the overall structure of the movements; the nature and features of their implementation). The main difference, which also serves as the most important biomechanical criterion for the effectiveness of technique implementation, is the time duration. Conclusions. The results of comparative analysis of techniques, performed by experienced employees and cadets of the fourth year of study allowed to establish that the composition of motor actions is the same in these groups, i.e. there are seizures, there are strikes, medial and lateral rotations of the upper imaginary offenders' extremities and more. One of the most important features is the structural sequence of these motor actions.

Key words: video recording of motor action technique, drills of "elbow lever outward", "elbow lever inwards" and "throw with legs grab behind".

Постановка наукової проблеми. Біомеханіка - одна 3 найстаріших гілок біології. Ї̈̈ джерелами були роботи Аристотеля і Галена, присвячені аналізу рухів тварин і людини. Але тільки завдяки роботам одного з найблискучіших людей епохи Відродження - Леонардо да Вінчі- біомеханіка зробила свій наступний крок. Леонардо да Вінчі описав механіку тіла при переході 3 положення сидячи до положення стоячи, при ходьбі вгору і вниз, при стрибках $[8,11,12,13,15]$.

Рухи людини підкоряються всім фізичним законам, які визначають рух будьякого матеріального тіла на Землі. Це - і закон всесвітнього тяжіння, і закони Ньютона, і закони гідроаеромеханіки, коливальних і хвильових явищ і т.п. Рухи, як правило, дуже складні, оскільки руховий апарат людини являє собою многозвену механічну систему, що складається 3 більш ніж 200 кісток і декількох сотень сухожиль. Загальна кількість можливих рухів в суглобах (так званих ступенів свободи) перевершує 250, число м'язів, які обслуговують руху, більше 600 . Все це необхідно для забезпечення чисто механічного переміщення людини у зовнішньому середовищі [9, 11-15].

Переважна більшість рухів людини виконується з певною метою і відноситься до числа довільних. Такі руху входять до складу рухових дій, в сукупність елементарних рухових актів, спрямованих на досягнення певної мети. У кожному руховому акті присутні орієнтовна, виконавча і контрольна частини $[11,12,13,15$, $16]$.

Виконавча частина - це і $є$ механічний рух. але воно завжди визначається психічної і фізіологічної діяльністю мозку, що забезпечує не тільки безпосереднє управління рухом, а й орієнтовну і контрольну частини рухової дії по системам біологічної внутрішнього зворотного зв'язку. Звідси, рух людини - це взаємодія його внутрішніх систем із зовнішнім оточенням $[11,12,13,15,17]$. Ще Аристотель писав: «Тварина, яка рухається, здійснює свою зміну положення шляхом натискання на те, що знаходиться під ним». Р.М. Енока ставив проблему розгляду руху як результату взаємодії біологічної системи і їі зовнішнього оточення через функціонування нейромеханічних систем організму (це те, що можна назвати внутрішньої, т. е. біологічно сформованою системою управління). А.М. Лапутін, І.П. Ратов і Г.І. Попов розширили цей підхід, стверджуючи, що рухи людини і їх вдосконалення слід розглядати як результат не просто взаємодії із зовнішнім середовищем, а взаємодії, при якому фізичні властивості зовнішнього середовища цілеспрямовано змінюються. А це означає, що таким способом можна цілеспрямовано впливати на сам характер руху через пристосувальні рухові реакції людини в умовах безперервного взаємодії із зовнішнім середовищем (то, що 
можна назвати зовнішнім управлінням). Отже, в управлінні рухами існують внутрішня і зовнішні системи управління, узгоджене функціонування яких дозволяє побудувати рухову дію людини $[11,12,13,15,18]$.

Виникнення і розвиток вітчизняної дидактичної біомеханіки пов'язано з ім'ям видатного вченого А.М. Лапутіна $[10,11,12]$. Глибокий мислитель i експериментатор, людина 3 колосальним і дивним світоглядом, великодушний гуманіст по суті А.М. Лапутін заклав основи вітчизняної біомеханіки і кінезіології. Його перу належать понад 160 науково-методичних праць, багато 3 яких опубліковані за кордоном. Неймовірне за охопленням і унікальне по глибині наукова спадщина А.М. Лапутін надавало і надає величезний вплив на розвиток біомеханіки і кінезіології в Україні. А.М. Лапутін володів дивовижною здатністю бачити перспективи розвитку науки, прогнозувати її головні напрямки $[11,12]$.

Мета дослідження - провести порівняльний біомеханічний аналіз техніки виконання прийомів «важіль ліктя назовні», «важіль ліктя всередину» та «кидок із захватом ніг ззаду» працівниками 3 досвідом роботи та курсантами четвертого року навчання з використанням оптико-електронної системи «Qualisys».

Методи дослідження. Для виконання поставлених завдань використано такі методи дослідження, як аналіз науково-методичної літератури й документальних матеріалів, методи реєстрації та аналізу рухів спортсмена (система відеореєстрації та аналізу рухів спортсмена 3D реєстрації рухів людини «Qualisys Motion Capture») [3, 6, 7, 10, 19]. Результати, отримані в процесі дослідження, було оброблено 3 використанням методів математичної статистики.

Виклад основного матеріалу дослідження. Дослідження останнього часу дають достатньо підстав для визнання того, що в сучасній спортивній науці утвердився самостійний напрям - дидактична біомеханіка $[1,2,4,5]$.

Порівняльний біомеханічний аналіз техніки виконання прийомів «важіль ліктя назовні», «важіль ліктя всередину» та «кидок із захватом ніг ззаду» працівниками 3 досвідом роботи та курсантами четвертого року навчання дозволив виявити принципові відмінності, які, на нашу думку, мають бути враховані в процесі навчання та удосконалення техніки зазначених прийомів курсантів.

Результати досліджень свідчать про наявність як загальних відмінностей у техніці виконання цих прийомів (загальна тривалість виконання прийому; етапність вирішення рухових завдань (паралельність або послідовність виконання рухових дій); техніка ударних дій), так і часткових, які характерні для окремих складових конкретного прийому (тривалість і послідовність окремих дій у загальній структурі прийому; характер та особливості їх виконання) $[1,2]$.

Головною відмінністю, яка слугує одночасно найбільш вагомим біомеханічним критерієм ефективності реалізації прийомів, $є$ тривалість часу.

Загальна тривалість рухових дій під час виконання прийомів у курсантів четвертого року навчання в середньому більша на 31,6 \% порівняно з працівниками 3 досвідом роботи (тривалість виконання прийому «важіль ліктя назовні» в середньому більша на 23,1 \%, «важіль ліктя всередину» - на 34,4 \%, «кидок із захватом ніг ззаду» на $37,3 \%(\mathrm{p}<0,05))[1,2]$.

На перший погляд, отримані показники не мають принципового значення, адже абсолютна різниця тривалості часу виконання прийомів не перевищує $1,1 \mathrm{c}$.

Проте важливо розуміти, що загальне збільшення часу на виконання прийомів курсантами четвертого року навчання припадає, передусім, саме на першу його частину, яка обгрунтовано є найбільш відповідальною.

А враховуючи те, що латентний період рухової реакції людини (від моменту прояву певних сигналів і до моменту початку виконання нею певних дій) значно 
менший за 1 с (залежно від віку, стану здоров'я, нервової системи, опорно-рухового апарату, наявності певного рухового досвіду, в тому числі спортивного тощо, - в середньому від 0,2 до 0,6 c), цього часу може бути достатньо для того, щоб затримуваний розпочав захисні, контратакуючі або інші дії, що вплине на подальший розвиток подій щодо затримання (необхідність внесення ситуаційних та непередбачуваних корекцій у технічне виконання прийому, можливість завдання небажаних травм як працівникові правоохоронних органів, так і правопорушникові, загальне збільшення тривалості затримання за часом тощо).

Утім, збільшення часу на виконання прийомів «важіль ліктя назовні», «важіль ліктя всередину» та «кидок із захватом ніг ззаду» курсантами четвертого року навчання слід розглядати не як помилку, яку необхідно виправити, а як наслідок певних дій, у яких закладено помилки, що зумовлюють загальне збільшення часу.

Результати порівняльного аналізу техніки виконання прийомів працівниками 3 досвідом роботи та курсантами четвертого року навчання дали змогу встановити, що склад рухових дій у цих групах однаковий, тобто відбуваються захвати, присутні ударні дії, медіальні й латеральні оберти верхніх кінцівок умовного правопорушників та інше. Однією з найбільш важливих особливостей є структурна послідовність цих рухових дій.

Так, при виконанні прийому «важіль ліктя назовні» 3 нанесенням першого удару рукою в працівників із досвідом роботи структурна послідовність рухових дій така: захват умовного правопорушника за кисть лівою рукою - удар правою рукою - захват умовного правопорушника за кисть правою рукою - падіння умовного правопорушника на спину - початок замаху правою рукою для виконання удару - положення умовного правопорушника лежачи, обличчям до підлоги - удар правою рукою.

У курсантів четвертого року навчання спостерігається дещо інша послідовність: удар правою рукою - захват умовного правопорушника за кисть лівою рукою - захват умовного правопорушника за кисть правою рукою - падіння умовного правопорушника на спину - положення умовного правопорушника лежачи, обличчям до підлоги початок замаху правою рукою для виконання удару - удар правою рукою.

3 отриманих даних видно, що працівник із досвідом роботи свої перші дії спрямовує на нейтралізацію ймовірних та небажаних рухових дій умовного правопорушника, тому із самого початку виконує захват кисті затримуваного й після цього проводить удар рукою. Курсанти четвертого року навчання, навпаки, спочатку проводять удар і лише після цього виконують захват кисті умовного правопорушника однією, а згодом (у середньому після 0,237 с $(\mathrm{S}=0,034))$ другою рукою.

При такій послідовності дій, а саме удар - захват, певною мірою втрачається контроль над умовним правопорушником, адже реакція на виконання ударної дії з його боку може бути непередбачуваною. По-перше, затримуваний має можливість виконувати захисні дії (закриття верхніми кінцівками зон тіла, у які наноситься удар; зміна положення та пози свого тіла, відстані до виконавця прийому тощо).

По-друге, курсант четвертого року навчання, в разі успішного виконання прийому, витрачає, як правило, певний час на те, щоб виконати захват кисті умовного правопорушника. Адже після отриманого удару верхні кінцівки умовного правопорушника виконують певні рухові дії, які є небажаними для виконавця прийому у зв'язку з необхідністю (для захвату кисті затримуваного) координувати власні рухи відповідно до дій умовного правопорушника. Більше того, в результаті отриманого больового шоку від удару затримуваний, як свідчить практика, значно напружується й подальше керування його тілом (у тому числі верхніми кінцівками) вимагає додаткових зусиль від виконавця прийому, на що також витрачається час (тривалість якого може коливатися в значних межах), а оскільки на виконання удару з подальшою фіксацією 
кисті обома руками курсанти четвертого року навчання витрачають у середньому 0,940 с $(S=0,050)$, затримуваний може здійснити певні захисні або контратакуючи дії.

Працівник із досвідом роботи на виконання захвату кисті умовного правопорушника обома руками та проведення удару витрачає в середньому 1,037 с $(\mathrm{S}=0,030)$. При цьому перша дія, захват умовного правопорушника за кисть лівою рукою, триває майже півсекунди $(0,482$ с $(\mathrm{S}=0,059))$.

Усі подальші рухи: удар правою рукою та захват цією ж рукою кисті умовного правопорушника, - становлять 0,555 с $(\mathrm{S}=0,040)$. Опитування працівників із досвідом роботи показало, що повільність першого руху, який насправді можна пришвидшити в декілька разів, як це характерно для курсантів четвертого року навчання, зумовлена необхідністю залишатися мінімально інформативним стосовно рухових дій, які працівники планують реалізувати щодо затримання.

Саме 3 цих міркувань виконання захвату можна умовно поділити на дві складові: піднесення робочої біоланки працівника 3 досвідом роботи до кисті умовного правопорушника та власне захват. Перша частина, як свідчить практика, має бути досить повільною, друга ж виконується максимально швидко та впевнено.

Отже, в зазначений відрізок часу, коли працівник із досвідом роботи виконує захват кисті (обома руками) та удар, додатково вирішуються вказані вище тактичні завдання.

На виконання самого удару рукою працівники витрачають близько 0,310 с $(S=0,016)$, що майже на 0,100 с швидше, ніж у виконанні курсантів четвертого року навчання $(\mathrm{p}<0,05)$. При цьому внаслідок зазначеної послідовності рухів працівник із досвідом роботи захват правою рукою кисті

умовного правопорушника здійснює в середньому через 0,245 с $(\mathrm{S}=0,019)$ після виконання нею удару; у курсантів четвертого року навчання цей час становить близько 0,535 c $(\mathrm{S}=0,030)(\mathrm{p}<0,05)$.

Важливо також, що з моменту, коли кисть умовного правопорушника утримує обома руками працівник правоохоронних органів, і до моменту, коли затримуваний лежить спиною на опорі, працівники з досвідом роботи витрачають $0,626 \mathrm{c}(\mathrm{S}=0,054), \mathrm{y}$ той час як курсанти четвертого року навчання - близько $1,014 \mathrm{c}(\mathrm{S}=0,061)(\mathrm{p}<0,05)$.

Аналіз рухових дій, що реалізуються в цей проміжок часу, вказує на те, що працівник із досвідом роботи 3 моменту захвату кисті умовного правопорушника виконує досить інтенсивне латеральне скручування всієї верхньої кінцівки затримуваного, супроводжуючи цей оберт додатковим лінійним переміщенням уздовж вертикалі донизу, що сприяє зменшенню загальної відстані, яку долає ЦМ кисті затримуваного в зазначений проміжок часу. А оскільки верхня кінцівка умовного правопорушника латерально обернена по відношенню до його тулуба та завдає йому больових відчуттів, напрям руху ЦМ кисті затримуваного, що задає працівник правоохоронних органів, буде зумовлювати відповідний напрям руху всього тіла умовного правопорушника (його ЗЦМ тіла).

Така траєкторія руху ЦМ кисті (рис. 1) приводить до швидкого падіння тіла умовного правопорушника на підлогу, що умовно на 80-90\% гарантує необхідну результативність виконання прийому. 


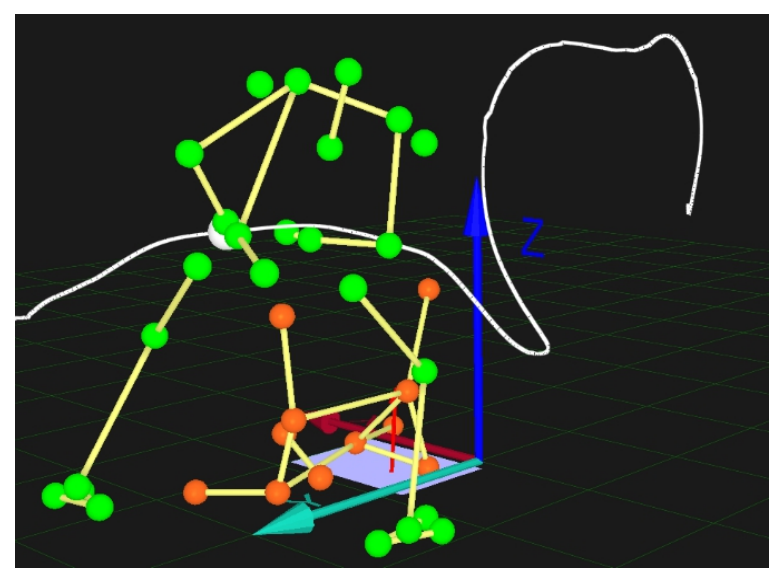

Рис. 1. Траєкторія руху ЦМ кисті умовного правопорушника при виконанні працівником із досвідом роботи латерального оберту верхньої кінцівки затримуваного (роздруківка з екрану монітора програми «Qualisys»)

В той же час у курсантів четвертого року навчання техніка виконання латерального скручування верхньої кінцівки затримуваного характеризується іiі обертом із значним горизонтальним переміщенням ЦМ кисті, що принципово змінює характер та, навіть, причини падіння затримуваного на спину.

Йдеться про те, що в результаті такої техніки латерального оберту верхньої кінцівки з горизонтальним переміщенням ЦМ кисті затримуваного курсант четвертого року навчання мусить також переміщуватися відповідно до заданої траєкторії (рис. 2).

При цьому, як показують експериментальні дані, внаслідок таких дій курсанта четвертого року навчання затримуваний (його ЗЦМ тіла) певний час залишається відносно нерухомим, що приводить до розгинання та відведення у плечовому суглобі останнього. В такому разі падіння відбувається не за рахунок чітких керованих дій працівника правоохоронних органів, у результаті яких затримуваний відносно самостійно наближає положення ЗЦМ власного тіла до опори, а шляхом виведення тіла умовного правопорушника зі стану рівноваги (реалізується механізм, при якому рука затримуваного використовується як важіль для передачі курсантом четвертого року навчання горизонтальної складової сили, що і приводить до падіння умовного правопорушника на спину).

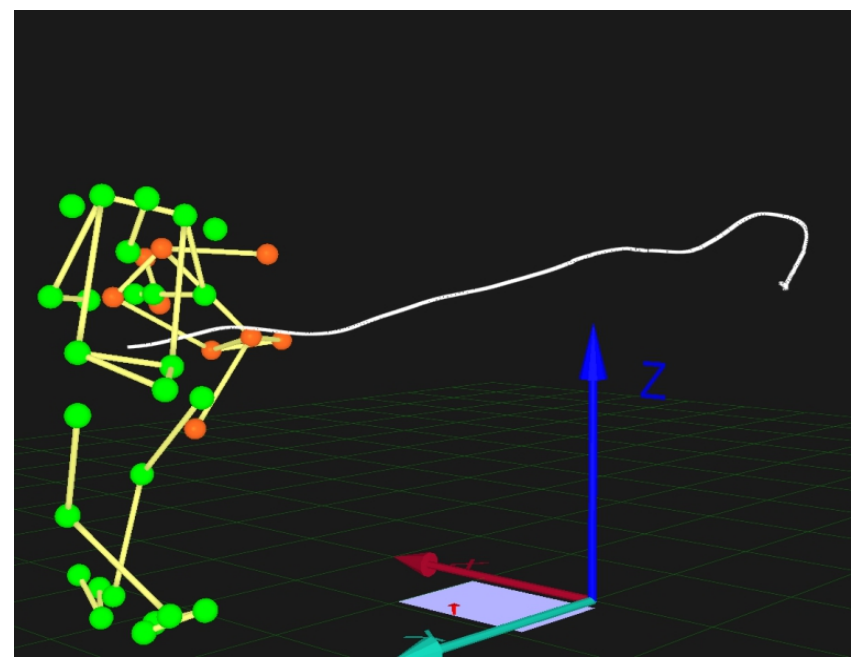

Рис. 2. Траєкторія руху ЦМ кисті умовного правопорушника при виконанні курсантом четвертого року навчання латерального оберту верхньої кінцівки затримуваного (роздруківка з екрану монітора програми «Qualisys») 
Такий спосіб реалізації латерального оберту є певною мірою неефективним, особливо в тому випадку, коли умовний правопорушник здійснює переміщення власного тіла (ЗЦМ тіла) за ходом горизонтального переміщення ЦМ його кисті, що значно вливає не тільки на збільшення загального часу виконання всієї вправи, але й на характер подальших рухів.

Отже, при такій послідовності рухових дій та характері виконання окремих технічних елементів загальний час виконання прийому курсантами четвертого року навчання збільшується $[1,2]$.

Висновки. Результати порівняльного аналізу техніки виконання прийомів працівниками 3 досвідом роботи та курсантами четвертого року навчання дали змогу встановити, що склад рухових дій у цих групах однаковий, тобто відбуваються захвати, присутні ударні дії, медіальні й латеральні оберти верхніх кінцівок умовного правопорушників та інше. Однією з найбільш важливих особливостей є структурна послідовність цих рухових дій.

Перспективи подальших досліджень будуть пов'язані з розробкою концепції формування базової техніки рукопашного бою у юних спортсменів.

\section{Список літературних джерел}

1. Вако І. Кількісна біомеханічна характеристика базової техніки рукопашного бою курсантів у процесі спеціальної фізичної підготовки Молодіжний науковий вісник Східноєвропейського національного університету імені Лесі Українки. 2015.17.33-38.

2. Вако I.І. Особливості техніки рукопашного бою у процесі спеціальної фізичної підготовки курсантів. Науковий часопис Національного педагогічного університету імені М.П. Драгоманова (Сер. № 15: Науково-педагогічні проблеми фізичної культури / Фізична культура і спорт) / за ред. Г.М. Арзютова. - К. : НПУ імені М.П. Драгоманова, 2015. 6 (62).17-20.

3. Кашуба В.А., Хмельницкая И.В. Современные оптико-электронные методы измерения и анализа двигательных действий спортсменов высокой квалификации Наука в олимп. спорте. 2005.2. 137-146.

4. Кашуба ВА, Литвиненко ЮВ, Данильченко ВА. Моделирование движений в спортивной тренировке. Физическое воспитание студентов. 2010;(4):40-4.

5. Кашуба ВА, Литвиненко ЮВ, Зарудный ВЮ, Беленко СС. Биомеханические аспекты техники ударных действий в восточных единоборствах. Теория и методика физической культуры. 2012;4(31):90-6.

6. Кашуба ВА, Литвиненко ЮВ, Юхно ЮА, Зарудний ВЮ, Беленко СС. Теоретико-практические аспекты использования оптико-электронных систем регистрации движений при биомеханическом анализе спортивной техники. Молодіжний науковий вісник Східноєвроп. нац. ун-ту ім. Лесі Українки. 2013;(9):7-15.

7. Кашуба ВА, Литвиненко ЮВ, Гордеева МВ, Зарудный ВЮ. Биомеханика спортивных движений и современные видеокомпьютерные методы их контроля. Теория и методика физической культуры. 2013;4(35):31-7.

8. Кашуба ВА. К вопросу использования современных технологий в спортивной подготовке Молодіжний науковий вісник Східноєвропейського національного університету імені Лесі Українки. Фізичне виховання і спорт: журнал / уклад. А. В. Цьось, А. І. Альошина. - Луцьк: Східноєвроп. нац. ун-т ім. Лесі Українки, 2015.19.171-183.

9. Кашуба ВА Инновационные технологии в современном спорте Спортивний вісник Придніпров'я - науково-практичний журнал Дніпропетровського державного інституту фізичної культури і спорту. 2016. 1.46-57. 
10. Кашуба ВА, Гордеева МВ, Жук АА, Ризатдинова АС, Литвиненко ЮВ. Программа повышения эффективности техники двигательных действий в видах спорта со сложнокоординационной структурой движения. В: Știinţa culturii fizice. Revistă teoretico-știinţifică. № 27/1. Chisinau: Universitatea de Stat de Educaţie Fizică și Sport, Publicaţie știinţifi că recenzată (Categoria „C”); 2017. 93-8.

11. Лапутин АН. Дидактическая биомеханика: проблемы и решения. В журн. "Наука в олимпийском спорте", № 2(3). Киев, 1995, с. 42-51.

12. Лапутін АМ, Кашуба ВО. Кінетика тіла людини: Навчальна програма для ВН3 фізичного виховання та спорту. Київ: Науковий світ, 2003.13 с.

13. Лапутін АМ, Кашуба ВО, Хабінець ТО. Кінетика як система знань про рухову функцію тіла людини. // Теорія і методика фізичного виховання і спорту К.: 2004, №2. - C. 96-102.

14. Лебедь О.О., Гаращенко В.І., Григус І.М. Біологічна та медична механіка: навч. посіб. Рівне: НУВГП, 2016. 186 с.

15. Попов ГИ, Самсонова АВ. Биомеханика двигательной деятельности: учеб. для студ. учреждений высш. проф. образования М., 2013. 320 с.

16. Diachenko-Bohun, M., Hrytsai, N., Grynova, M., Grygus, I., Muszkieta, R., Napierała, M., Zukow, W. (2019). Characteristics of Healthbreakers in the Conditions of Realization of Health-Safety Technologies in Education Structures. International Journal of Applied Exercise Physiology, 8(3.1), 24-32. DOI: https://doi.org/10.30472/ijaep.v8i2.391

17. Kashuba V., Stepanenko O., Byshevets N., Kharchuk O., Savliuk S., Bukhovets B., Grygus I., Napierała M., Skaliy T., Hagner-Derengowska M., Zukow W. (2020). The Formation of Human Movement and Sports Skills in Processing Sports-pedagogical and Biomedical Data in Masters of Sports. International Journal of Human Movement and Sports Sciences, 8(5): pp. 249-257. DOI: 10.13189/saj.2020.080513

18. Pelech I.V., Grygus I.M. Level of physical fitness students. Journal of Education, Health and Sport. 2016;6(2):87-98.

19. http://www.qualisys.com

1. Wako I. Kilkisna biomechanical characteristic of the basic technique of hand-tohand combat cadets in the process of special physical training. 2015.17.33-38.

2. Wako I. I. Special features of hand-to-hand combat techniques in the process of special physical training of cadets Science hour writing of the National Pedagogical University named after M. P. Dragomanov (Ser. No. 15: Scientific and pedagogical problems of physical culture / physical sports) for culture G.M. Arzyutova. - K.: NPU imene M. P. Dragomanova, 2015.6 (62) .17-20.

3. Kashuba VA, Khmelnitskaya IV Modern optoelectronic methods of measuring and analyzing motor actions of highly qualified athletes Science in Olymp. sports. 2005.2. 137146.

4. Kashuba VA, Litvinenko YuV, Danilchenko VA. Simulation of movements in sports training. Physical education of students. 2010; (4): 40-4.

5. Kashuba VA, Litvinenko YV, Zarudny VYu, Belenko SS. Biomechanical aspects of percussion technique in martial arts. Theory and methodology of physical culture. 2012; 4 (31): 90-6.

6. Kashuba VA, Litvinenko YuV, Yukhno YuA, Zarudny VYu, Belenko SS. Theoretical and practical aspects of the use of optical-electronic systems for registration of movements in biomechanical analysis of sports equipment. Young Science Visnik Skhidnoevrop. nat. un-tu im. Lesi Ukrainka. 2013; (9): 7-15. 
7. Kashuba VA, Litvinenko YuV, Gordeeva MV, Zarudny VYu. Biomechanics of sports movements and modern video-computer methods of their control. Theory and methodology of physical culture. 2013; 4 (35): 31-7.

8. Kashuba VA On the issue of using modern technologies in sports training. Youth Science Visitor of the Skhidnoevropeyskiy National University of Lesya of Ukraine. Physical behavior and sport: magazine / way. A. V. Ts'os, A. I. Aloshin. - Lutsk: Skhidnoevrop. nat. un-t im. Lesi Ukrainka, 2015.19.171-183.

9. Kashuba VA Innovative technologies in modern sports Sports visnik of Pridniprov'ya - a scientific and practical journal of the Dnipropetrovsk State Institute of Physical Culture and Sports. 2016. 1.46-57.

10. Kashuba VA, Gordeeva MV, Zhuk AA, Rizatdinova AS, Litvinenko YuV. The program for improving the efficiency of motor actions technique in sports with a complex coordination structure of movement. In: Știinţa culturii fizice. Revistă teoretico-știinţifică. No. 27/1. Chisinau: Universitatea de Stat de Educaţie Fizică și Sport, Publicaţie ştiinţifi că recenzată (Categoria „C”); 2017.93-8.

11. Laputin AN. Didactic biomechanics: problems and solutions. In the journal. "Science in Olympic Sports", No. 2 (3). Kiev, 1995, p. 42-51.

12. Laputin AM, Kashuba VO. Kinetics tila people: Navchalna program for VNZ physical vikhovannya and sports. Kiev: Naukoviy svit, 2003, 13 p.

13. Laputin AM, Kashuba VO, Khabinets TO. Kinetics is a system of knowledge about the rukhov function of tila people. // Theory and methodology of physical education and sport K .: 2004, №2. - S. 96-102.

14. Lebed O.O., Harashchenko V.I., Grygus I.M. Biolohichna ta medychna mekhanika: navch. posib. Rivne: NUVHP, 2016. $186 \mathrm{~s}$.

15. Popov GI, Samsonova AV. Biomechanics of motor activity: textbook. for stud. institutions of higher. prof. Education M., 2013.320 p.

16. Diachenko-Bohun, M., Hrytsai, N., Grynova, M., Grygus, I., Muszkieta, R., Napierała, M., Zukow, W. (2019). Characteristics of Healthbreakers in the Conditions of Realization of Health-Safety Technologies in Education Structures. International Journal of Applied Exercise Physiology, 8(3.1), 24-32. DOI: https://doi.org/10.30472/ijaep.v8i2.391

17. Kashuba V., Stepanenko O., Byshevets N., Kharchuk O., Savliuk S., Bukhovets B., Grygus I., Napierała M., Skaliy T., Hagner-Derengowska M., Zukow W. (2020). The Formation of Human Movement and Sports Skills in Processing Sports-pedagogical and Biomedical Data in Masters of Sports. International Journal of Human Movement and Sports Sciences, 8(5): pp. 249-257. DOI: 10.13189/saj.2020.080513

18. Pelech I.V., Grygus I.M. Level of physical fitness students. Journal of Education, Health and Sport. 2016;6(2):87-98.

19. http: //www.qualisys.com 